\title{
Epidemiology, Clinical, and Therapeutic Aspects of Paracoccidioidomycosis
}

\author{
Maurimélia Mesquita da Costa • Silvia Helena Marques da Silva
}

Published online: 1 March 2014

(C) Springer International Publishing AG 2014

\begin{abstract}
Paracoccidioidomycosis, or PCM, was described by Adolfo Lutz 105 years ago. Since then the disease has taken a prominent position among the systemic fungal infections because it mainly affects individuals in the most productive years of their lives in various countries of Latin America. In Brazil, the disease is considered endemic in some regions. However, it is still a neglected disease. With the recent discovery that Paracoccidioides brasiliensis is not the only species of this genus, numerous studies have contributed to better understanding and recognition of this pathogen and its pathology in many aspects, such as the epidemiological, clinical, and therapeutic aspects.
\end{abstract}

Keywords Paracoccidioidomycosis (PCM)) .

Epidemiology $\cdot$ Clinical aspects · Therapeutics · Tropical medicine $\cdot$ Latin America $\cdot$ P. brasiliensis $\cdot$ Tropical mycosis . Systemic mycosis $\cdot$ Mycosis $\cdot$ Infectious disease

\section{Introduction}

Paracoccidioidomycosis (PCM) is a granulomatous and progressive systemic mycosis in Latin American countries, occurring mainly in Brazil, Colombia, and Venezuela [1•]. An infectious disease with high morbidity and commonly found in poor areas, it is known as South American blastomycosis, Lutz illness, and Lutz-Splendore-Almeida disease, because Splendore was the first to cultivate the pathogen and Almeida was the author of the first study of the disease [2].

M. M. da Costa $(\bowtie) \cdot$ S. H. Marques da Silva

Instituto Evandro Chagas - Seção de Bacteriologia e Micologia,

Laboratório de Micologia, Rodovia BR 316, Km 07 s/nº, Levilândia,

Ananindeua, Pará, Brazil 67.030-000

e-mail: maurimesq@gmail.com
PCM is caused by the cryptic species Paracoccidioides brasiliensis (species S1, PS2, and PS3) [3] and P.lutzii [4, 5•, $6 \bullet]$. It is a thermally dimorphic fungus, which grows as a yeastlike structure in host tissues or when cultured at $35-37^{\circ} \mathrm{C}$ and as a mycelium under saprobic conditions, producing infective asexual spores or conidia at $18-23^{\circ} \mathrm{C}$ (Fig. 1) [7].

\section{Epidemiology}

PCM is acquired through inhalation of spores present in the environment and is often associated with outdoor activities and geographic exposure, but other predisposing factors, such as gender, age, tobacco use, alcohol consumption, socioeconomic conditions (poverty), and working conditions (farming and agriculture, specifically in cotton, coffee, and tobacco plantations), are associated with this pathology $[8 \cdot, 9,10]$.

Paracoccidioides has been repeatedly recovered from human clinical samples and tissues from some armadillo species (Dasypus novemcinctus) [11, 12], and the first association with these animals was observed in the Amazon region by Naiff et al. [13]. Although the Paracoccidioides was recovered from soil and related material in many situations, the exact places where this fungus exists in nature have not yet been determined; however, the soil continues to be an important element in the ecological study of this fungus [14].

Evidence indicates that mycelial forms occur in the soil under restrictive conditions. Propagules such as arthroconidia and aleuroconidia produced by mycelium and present in the environment may be inhaled and are subsequently transformed into yeast, which causes primary infection in the lung [15] and is then spread by blood and lymphatic vessels, reaching different organs and systems and resulting in lesions in the skin, lymph nodes, and mucous membranes [16, 17]. In addition, these propagules can induce animal infection by the respiratory route [18]. Natural infection in some domestic 
Fig. 1 Morphological characteristics of

Paracoccidioides. A, Yeast in tissue host. B, Yeast culture. C, Filament form (macrocolony). D, Filament form with conidia and other propagules (slide culture). E, Yeast form (culture)
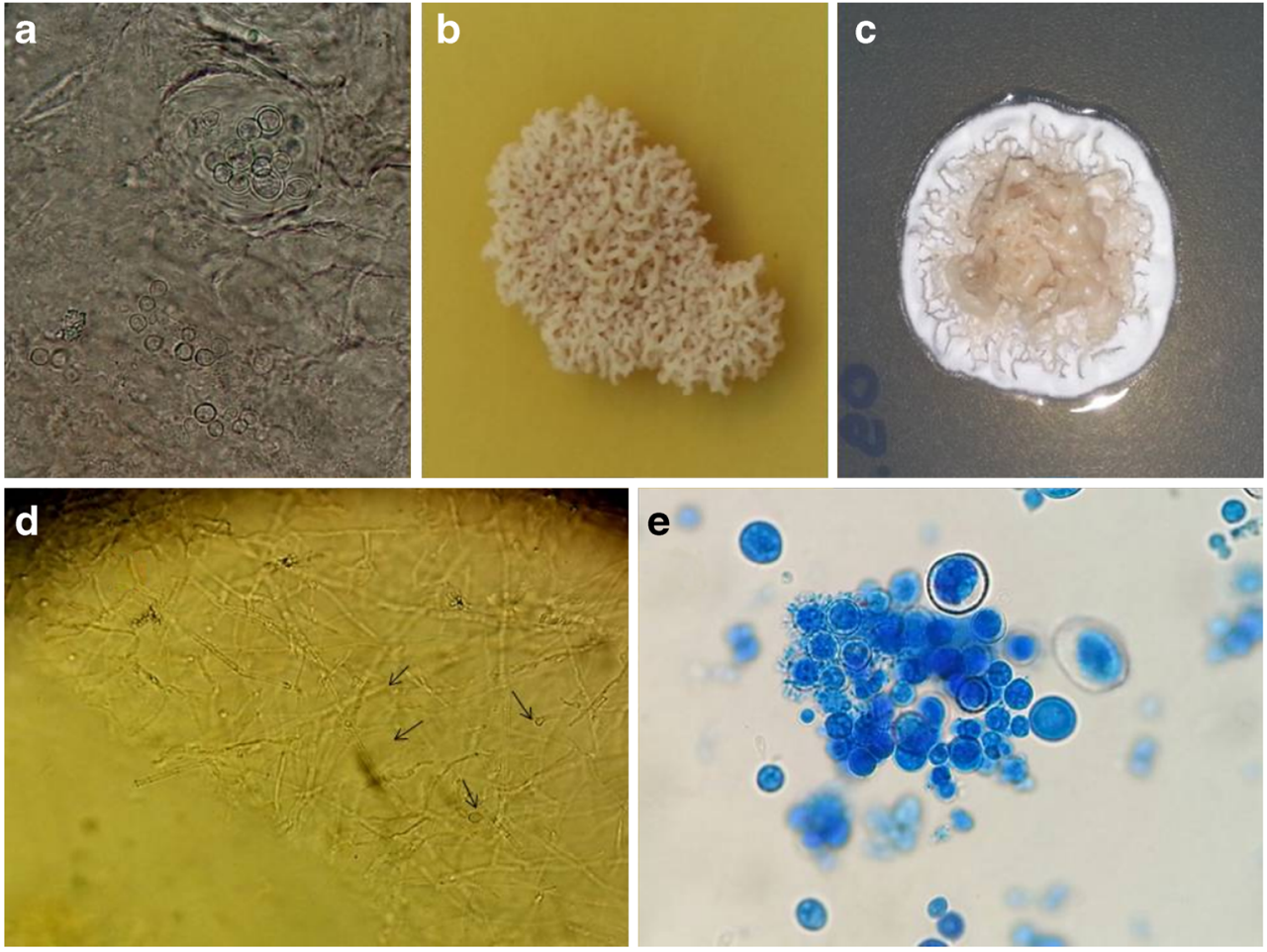

animals has been observed by intradermal and serological tests. In Brazil, seroepidemiological tests have been used in urban and rural canine populations. Enzyme-linked immunosorbent assay (ELISA) and immunodiffusion methodology were used to investigate the prevalence of anti-P.brasiliensis antibodies in 305 dogs from the Londrina region. The study showed positivity rates ranging from $14.5 \%$ to $89.5 \%$, using the ELISA technique [19]. In addition, in 2004, the first confirmed case of paracoccidioidomycosis in a dog with a strictly urban life was reported [20].

South America has a range of climatic characteristics and rich biodiversity, which facilitate the development of various fungal pathogens in different habitats. In many countries of Latin America, principally in Brazil, there are regions with a large population of rural workers who are engaged in agricultural activities and are exposed to diverse fungal habitats in the soil [10-20, 21•].

The ecological characteristics of the endemic areas of PCM suggest that the pathogen preferentially inhabits humid environments with average annual temperatures between $18{ }^{\circ} \mathrm{C}$ and $24^{\circ} \mathrm{C}$ and high annual rainfall $(900-1,800 \mathrm{~mm})$ [15].

In Brazil, PCM has a heterogeneous distribution, with low and high areas of endemicity. The disease has considerable public health importance, with high social and economic costs, since it occurs in individuals at their most productive age, causing frequent sequelae, and is a common cause of work disability. Although the disease remains a serious social problem, it is impossible to establish its true distribution because the disease is not notifiable in the Public Health
System in Brazil, where the status of this endemic systemic mycosis in various regions is difficult to assess [22]. On the other hand, in any Brazilian state, such as Minas Gerais, Mato Grosso do Sul, and Rondônia, PCM is considered a disease requiring compulsory notification, and in São Paulo it has been recommended that all confirmed cases of PCM be reported to the Health System [23•].

The real prevalence and incidence cannot be established precisely. Knowledge of endemic areas and prevalence, incidence, and morbidity data are based on case reports and scattered skin tests [10]. In addition, the mortality rates can be used as a tool to compare the incidence and severity of PCM with use of the regional data [24, 25•].

The prevalence of PCM varies from country to country and also, in the same country, from region to region. In Brazil, the South and Southeast regions have a high prevalence of the disease (as high as $75 \%$ ), affecting both men and women. The annual incidence is $10-30$ cases per $1,000,000$ inhabitants $[8 \cdot, 21 \bullet, 22,23 \bullet, 24,25 \bullet, 26]$. It is estimated that in endemic regions there are approximately 10 million people infected by Paracoccidioides. In regions such as Argentina, Venezuela, and Colombia, the incidence is lower (2.4 cases per 1,000,000 inhabitants) [8]. It should be stressed that in the endemic regions, the infection as measured by skin testing is far more prevalent than the disease. However, most people have no clinical symptoms of the disease, and cases like these have been reported in isolated case reports or as part of a series of patients [27]. 
The real number of patients with these systemic mycoses is unknown. Men are more susceptible to the disease, whereas women are infected during conditions of immunosuppression or probably as a consequence of hormonal changes [28•]. Studies have described a higher incidence in men than in women, with a ratio that ranges from 13:1 to 47:1, depending on the region $[29,30 \bullet$.

Restrepo-Moreno [31] and Fava and Fava-Neto [32], utilizing intradermal tests, suggested that the incidence of PCM infection without symptoms of the disease was high in endemic areas (2-60\%).

Coutinho et al. [24] studied 3,181 deaths from PCM in Brazil over a period of 15 years, showing a high prevalence of the disease, along with its low visibility. It was notably the eighth most common cause of death among chronic diseases and had the highest mortality rate among the systemic mycoses, such as cryptococcosis, pneumocystosis, and histoplasmosis in HIV-negative patients.

\section{Clinical Manifestations of Paracoccidioidomycosis}

\section{Forms of Paracoccidioidomycosis}

PCM can have several clinical presentations. In order to establish a better way to deal with them, in 1986 the International Colloquium on Paracoccidioidomycosis, which occurred in Medellín, Colombia [33], adopted a classification combining clinical data with the disease natural course, which was adapted by the Brazilian Guidelines in Paracoccidioidomycosis in 2006 [10]. By these criteria, PCM can be classified into two basic forms: PCM infection and PCM disease. PCM infection is usually demonstrated by a positive skin test and no specific symptoms are associated with it. PCM disease can occur in three forms: acute/subacute, chronic, and residual. The chronic form can also be unifocal or multifocal, according to the presence of lesions in one or more organs, respectively. These subforms can also be classified as light, moderate, or severe, depending on the severity of the manifestations (Table 1) [34•].

\section{The Acute/Subacute Form}

The acute/subacute form is also known as juvenile-type PCM since it is the clinical form that occurs in children, although it can occasionally be seen in adults under 35 years old. The symptoms include the presence of lymphoadenomegaly, gastrointestinal manifestations (including bowel obstruction or acute abdominal syndrome, which is the result of mesenteric lymph node hypertrophy [35]), cutaneous lesions, and osteoarticular symptoms [10, 34 $]$. In this form, which represents $3-5 \%$ of cases of PCM, the first signs of the disease usually arise up to 12 weeks after the beginning of the
Table 1 Forms of paracoccidioidomycosis (PCM)

\begin{tabular}{lll}
\hline Basic forms & Subforms & \\
\hline PCM infection & & \\
PCM disease & Acute/subacute & Unifocal \\
& Chronic & Multifocal \\
& Sequelae & \\
\hline
\end{tabular}

infection [10]. Cases of subacute PCM were reported by Fonseca et al. [36] among children in the city of Belém, Pará State, Brazil, showing that the most frequent symptoms were superficial lymph node enlargement (in $100 \%$ of cases), fever (in $92.3 \%$ ), weight loss (in $84.6 \%$ ), and increased abdominal volume (in $46 \%$ ). Other rare manifestations such as bone marrow necrosis can be seen in acute/subacute PCM, as described by Resende et al. [37] in a report of eight patients who were autopsied at Botucatu University Hospital. The most remarkable immunological aspect of acute/subacute PCM is depression of the cell-mediated response, which is important for disease control and leads to the worst prognosis, with high lethality [38].

\section{The Chronic Form}

The chronic form accounts for approximately $90 \%$ of cases of PCM and usually occurs in male adults. It presents with a long progression and the clinical signs involve the occurrence of pulmonary lesions, with general symptoms such as weakness, weight loss, cough, fever, anorexia, and dyspnea also being present [39]. The unifocal form accounts for $25 \%$ of chronic cases and is characterized by the presence of pulmonary lesions only. Extrapulmonary lesions are described as the multifocal form, where the fungus has disseminated to other organs, causing several different types of lesion, particularly involving the oral and nasal mucosa and the lymph nodes. But there are also other affected sites such as the gastrointestinal mucosa, liver, pancreas, central nervous system, adrenal glands, and bones [40, 41•]. Lesions in the pharyngeal and laryngeal mucosa, leading to dysphagia and odynophagia, and gingival lesions, leading to sialorrhea, are also common in this form of the disease [42].

Neuroparacoccidioidomycosis Neuroparacoccidioidomycosis is not as infrequent as it was thought to be. Medical imaging methods have allowed diagnosis of these cases, contributing to the higher incidence data shown in the literature. Prevalence rates are variable and reach up to $36 \%$ [43]. A review of 81 papers published between 1919 and 2007 described 257 cases of neuroparacoccidioidomycosis; most of them (93\%) were males presenting with motor deficits and intracranial hypertension, and $59.1 \%$ also presented with the pulmonary form 
of PCM. Mortality was high (44.1\%) and the prevalence of sequelae after resolution, particularly motor deficits, was also elevated (50.1\%) [44].

Gastrointestinal Manifestations Gastrointestinal involvement is another chronic PCM manifestation, which has been well documented by several reports. Symptoms that have been described, beyond the general ones, are abdominal pain, diarrhea, dysentery, hepatomegaly, splenomegaly, and ascites [45]. Weight loss is also an important sign. Martinez et al. [46] reported a case of colon paracoccidioidomycosis in a 22year-old man, who had lost 35 pounds in 5 months. Colonoscopy showed diffuse hyperemia of the mucosa and roundish reddened lesions, together with multiple ulcerations of the colon mucosa [46]. Eventually, intestinal PCM may be confused with colon cancer, as reported by Chojniak et al. [47], who described a case of an abdominal mass associated with intralesional calcifications in pseudotumoral PCM. The patient had been treated for an oropharyngeal PCM lesion 15 years before. Computed tomography imaging showed an abscessed area involving the psoas muscle, calcifications, and thickening of the bowel walls in the ileocecal area. Multiple granulomas, diffuse fibrosis, and reactive lymphoreticular hyperplasia was shown by histological study, confirming PCM [47].

Genitourinary Manifestations Genitourinary manifestations are considered rare occurrences in PCM; however, several case reports are found in the literature. Cases are mostly seen in men, since women are usually protected by feminine hormones [48]. In men, lesions can be present in the penis, scrotum, testicles, epididymis, and prostate $[49,50]$. A retrospective study described 11 cases of PCM showing male genital involvement, with lesions in the testicle or scrotum being the most frequent [51]. Another study found a $1.2 \%$ frequency of genitourinary involvement among 483 PCM patients in a 42-year period. All of them presented with lesions in the external genitalia and only one was a female patient, who had the juvenile PCM form [52•]. Lopes et al. [53] described a case of PCM confused with prostatic adenocarcinoma in a 54year-old man who had manifested palate stomatitis associated with odynophagia and dysphagia 5 years before. The patient also had dysuria, polyuria, urinary urgency, and, finally, urethral obstruction. Histological analysis revealed a diffuse chronic granulomatous inflammatory process and typical Paracoccidioides yeasts with multiple sprouting [53].

\section{The Disseminated Form}

Disseminated PCM is usually described in patients with immune dysfunction, not necessarily associated with HIV infection but as a consequence of other factors, such as age and habits that impair immunity (smoking, alcoholism, malnutrition). Lesions can be found in several anatomical sites and the clinical manifestations differ from case to case. For example, Araújo et al. reported a case in a 46-year-old man presenting with disseminated plaque-like ulcerated skin lesions, associated with pharyngeal, nasal, and laryngeal mucosal lesions [54-]. Another report described a 60-year-old man who lived in a rural area and had a clinical history of bloody sputum, dizziness, headache, nausea, and memory loss for 2 months. $\mathrm{He}$ also presented with multiple lesions in the brain and a mass in the thorax, which simulated metastatic lung cancer. An autopsy revealed central nervous system and pulmonary PCM together with pulmonary strongyloidiasis [55•].

Some of the disseminated cases are associated with HIV infection and can be manifested either as acute PCM or as disseminated PCM. The clinical manifestations are usually prolonged fever, weight loss, generalized lymphoadenopathy, skin lesions, splenomegaly, hepatomegaly, and pulmonary and central nervous system involvement [56]. Most of the cases are described in patients presenting with $\mathrm{T} \mathrm{CD} 4^{+}$lymphocyte counts of less than 200 cells $/ \mathrm{mm}^{3}$ [57]. Castro and Martinez [58] presented a case in a 32-year-old patient whose $\mathrm{T} \mathrm{CD} 4^{+}$lymphocyte count was 9 cells $/ \mathrm{mm}^{3}$. He had a 9month history of weight loss, weakness, ulcerated lesions all over his body, hepatomegaly, and lytic lesions on the bones of the hands, arms, legs, feet, and skull [58]. Another case of disseminated PCM showed the occurrence of peripleuritis and subcutaneous abscesses on the chest wall and sternum associated with enlargement of cervical lymph nodes and hepatosplenomegaly. The patient also presented with prolonged fever, weight loss, anorexia, and a $\mathrm{T} \mathrm{CD} 4^{+}$lymphocyte count of 8 cells $/ \mathrm{mm}^{3}$ [59].

\section{Sequelae}

Residual forms or sequelae usually involve impairment of the function of the organ/tissue affected by the disease, as a result of the chronic granulomatous inflammatory process, which leads to fibrosis after resolution [60]. The most commonly

Table 2 Treatment of paracoccidioidomycosis

\begin{tabular}{lcl}
\hline Drug & Dosage for adults & Period of treatment \\
\hline Itraconazole & $200 \mathrm{mg} /$ day & $\begin{array}{c}\text { Light forms: 6-9 months } \\
\text { Moderate forms: } 12- \\
18 \text { months }\end{array}$ \\
$\begin{array}{ccc}\text { Sulfamethoxazole/ } \\
\text { trimethoprim }\end{array}$ & $\begin{array}{c}160-240 \mathrm{mg}+800- \\
1,200 \mathrm{mg} / 12 \mathrm{~h}\end{array}$ & $\begin{array}{l}\text { Light forms: } 12 \mathrm{months} \\
\text { Moderate forms: } 18- \\
\text { 24 months }\end{array}$ \\
Amphotericin B & $\begin{array}{c}0.5-1.0 \mathrm{mg} / \mathrm{kg} / \text { day } \\
\text { or on alternate days }\end{array}$ & $\begin{array}{c}\text { Severe forms: until clinical } \\
\text { improvement }\end{array}$ \\
\hline
\end{tabular}

Adapted from Shikanai-Yasuda MA, Telles Filho Fde Q, Mendes RP, et al. Guidelines in paracoccidioidomycosis. Rev Soc Bras Med Trop. 2006; 39(3):297-310 
observed sequelae occur in the lungs, with the presence of chronic obstructive pulmonary disease in some cases [61]. Adrenal insufficiency can also be seen. Epilepsy, motor deficits, and hydrocephalus are observed as the result of central nervous system infection. Dysphonia, microstomia, and laryngeal obstruction are also reported [10].

\section{Therapeutic Aspects of Paracoccidioidomycosis}

The treatment of PCM requires not only the prolonged use of antifungal drugs but also global measures to stabilize the patient, i.e., treatment of comorbidities such as tuberculosis and HIV infection or the presence of nutritional problems. Patients must have their kidney and liver functions evaluated to ensure the best therapeutic choice. Cessation of smoking or drinking is recommended [34•].

Among the antifungal drugs, itraconazole is considered the drug of choice for treatment of PCM, with a dosage of $200 \mathrm{mg}$ /day for 6-9 months in adults presenting with the light form of the mycosis. In moderate forms the treatment is maintained for 12-18 months. Itraconazole is usually combined with sulfamethoxazole/trimethoprim in dosages of 160 $240 \mathrm{mg} / 12 \mathrm{~h}$ for trimethoprim and $800-1,200 \mathrm{mg} / 12 \mathrm{~h}$ for sulfamethoxazole. Sulfamethoxazole/trimethoprim therapy is maintained for 12 months in light forms and for 18-24 months in moderate forms. For severe forms the drug of choice is amphotericin B in a dosage of $0.5-1.0 \mathrm{mg} / \mathrm{kg} /$ day or on alternate days. For special groups such as children, pregnant women, and patients with liver or renal failure, other recommendations are necessary and must be evaluated specifically. Patients must be evaluated monthly during the first 3 months of treatment by serological, radiological, biochemical, and clinical criteria until they are cured (Table 2) [10].

Studies have been performed to investigate other kinds of therapy. The main strategies involve therapeutic vaccination using fungal antigens and the use of specific monoclonal antibodies in order to improve the cell immune response against the fungus [62•]. An immunodominant peptide called P10 [63], derived from the major antigen gp43, has been shown to be useful in eliciting the cellular immune response and was validated as a vaccine candidate [64] and proven to play a protective role in prophylactic and therapeutic experiments using infected mice [62•]. Although this and other strategies may need a long road to come into clinical use, they point to the possibility of increasing the therapeutic options in PCM treatment.

\section{Conclusions}

Since its first description, paracoccidioidomycosis has been well studied and information about the disease and its etiologic agents have been accumulated, and so the diagnosis, treatment, and control of cases have become easier and more effective. However, many other studies are needed to better comprehend not only the biology of the fungus, with the diversity of species that have now been found, but also the host-pathogen interactions, considering this new scenario. Establishing how the cryptic species are distributed in endemic areas, what kind of immune response they stimulate, and how to deal with them in terms of diagnostic techniques may be important steps to follow in order to help clinicians and patients most effectively.

\section{Compliance with Ethics Guidelines}

Conflict of Interest Maurimélia Mesquita da Costa and Silvia Helena Marques da Silva declare that they have no conflicts of interest in connection with this work.

Human and Animal Rights and Informed Consent This article does not contain any studies with human or animal subjects performed by either of the authors.

\section{References}

Papers of particular interest, published recently, have been highlighted as:

- Of importance

1. Marques SA. Paracoccidioidomycosis. Clin Dermatol. 2012;30: 610-5. The author discusses clinical and therapeutics aspects of PCM.

2. Moreira APV. Paracoccidioidomicose: histórico, etiologia, epidemiologia, patogênese, formas clínicas, diagnóstico laboratorial e antígenos. Boletim Epidem Paulista. 2008;51:1-16.

3. Matute DR, McEwen JG, Puccia R, et al. Cryptic speciation and recombination in the fungusParacoccidioides brasiliensis as revealed by gene genealogies. Mol Biol Evol. 2006;23:65-73.

4. Teixeira MM, Theodoro RC, Carvalho MJ, et al. Phylogenetic analysis reveals a high level of speciation in the Paracoccidioides genus. Mol Phylogenet Evol. 2009;52:273-83.

5. Marques-da-Silva SH, Rodrigues AM, de Hoog GS, et al. Occurrence of Paracoccidioides lutzii in the Amazon region: description of two cases. Am J Trop Med Hyg. 2012;87:710-4. This study describes the clinical, diagnostics and molecular aspects of 2 cases of patients with P. lutzii in the Amazon region.

6. Theodoro RC, Teixeira MM, Felipe MS, et al. Paracoccidioides genus: species recognition and biogeographic aspects. PLoS One. 2012;7:e37694. These investigators studied the use of morphological criteria as markers to distinguish between the four cryptic species of the genus Paracoccidioides, as well as biogeographic aspects of how these species might have diverged in South America.

7. McEwen JG, Bedoya V, Patiño MM, et al. Experimental murine paracoccidiodomycosis induced by the inhalation of conidia. J Med Vet Mycol. 1987;25:165-75.

8. Sifuentes-Osornio J, Corzo-León DE, Ponce-de-León LA. Epidemiology of invasive fungal infections in Latin America. Curr Fungal Infect Rep. 2012;6:23-34. This article discusses the 
epidemiology of invasive fungal infections and opportunistic and endemic mycoses in Latin America.

9. Santos WA, Silva BM, Passos ED, et al. A associação entre tabagismo e paracoccidioidomicose: um estudo de caso-controle no Estado do Espírito Santo. Brasil Cad Saúde Pública. 2003;19: 245-53.

10. Shikanai-Yasuda MA, Queiroz-Filho FT, Mendes RP, et al. Consenso em paracoccidioidomycosis. Rev Soc Bras Med Trop. 2006;39:297-310

11. Bagagli E, Franco M, Bosco SMG, et al. High frequency of Paracoccidioides brasiliensis infection in armadillo (Dasypus novemcinctus): an ecological study. Med Mycol. 2003;41:217-23.

12. Bagagli E, Bosco SM, Theodoro RC, et al. Phylogenetic and evolutionary aspects of Paracoccidioides brasiliensis reveal along coexistence with animal hosts that explain several biological features of the pathogen. Infect Genet Evol. 2006;6:344-51.

13. Naiff RD, Ferreira LC, Barrett TV, et al. Enzootic paracoccidioidomycosis in armadillos (Dasypus novemcinctus) in the State of Pará. Rev Inst Med Trop Sao Paulo. 1986;28:19-27.

14. Franco M, Bagagli E, Scapolio S, et al. A critical analysis of isolation of Paracoccidioides brasiliensis from soil. Med Mycol. 2000;38:185-91.

15. Restrepo A. The ecology of Paracoccidioides brasiliensis: a puzzle still unsolved. Sabouraudia. 1985;23:323-34.

16. Franco MF, Montenegro MRG, Mendes RP, et al. Paracoccidioidomycosis: a recently proposed classification of its clinical forms. Rev Soc Bras Med Trop. 1987;20:129-32.

17. Ramos-e-Silva M, Saraiva LE. Paracoccidioidomycosis. Dermatol Clin. 2008;26:257-69.

18. Lupi O, Tyring SK, McGinnis MR. Tropical dermatology: fungal tropical diseases. J Am Acad Dermatol. 2005;53:931-51.

19. Ono MA, Bracarense APFRL, Morais HAS, et al. Canine paracoccidioidomycosis: a seroepidemiological study. Med Mycol. 2001;39:277-85.

20. Ricci G, Mota FT, Wakamatsu A, et al. Canine paracoccidioidomycosis. Med Mycol. 2004;42:379-83.

21. Colombo AL, Tobón A, Restrepo A, et al. Epidemiology of endemic systemic fungal infections in Latin America. Med Mycol. 2011;49:785-98. This study reviews the epidemiology of the most clinically significant endemic mycoses in Latin America: PCM, histoplasmosis, and coccidioidomycosis.

22. Bittencourt JIM, Oliveira RM, Coutinho ZF. Paracoccidioidomycosis mortality in the State of Paraná, Brazil, 1980/1998. Cad Saúde Pública. 2005;21:1856-64.

23. Kamikawa CM, Kohara VS, Passos NA, et al. Retrospective seroepidemiological analysis of patients with suspicion of paracoccidioidomycosis in São Paulo State, Brazil. J Venom Anim Toxins Incl Trop Dis. 2012;18:261-71. These authors discuss the geographical distribution of PCM, using data obtained from routine serological analysis of patients.

24. Coutinho ZF, Silva D, Lazéra M, et al. Paracoccidioidomycosis mortality in Brazil (1980-1995). Cad Saúde Pública. 2002;18: 1441-54.

25. Bellissimo-Rodrigues F, Machado AA, Martinez R. Paracoccidioidomycosis epidemiological features of a 1 , 000 -cases series from a hyperendemic area on the southeast of Brazil. Am J Trop Med Hyg. 2011;85:546-50. This study reveals that endemic area is probably caused by geological and climatic conditions as well as intensive agriculture.

26. Nucci M, Colombo AL, Queiroz-Telles F. Paracoccidioidomycosis. Curr Fung Infect Rep. 2009;3:15-20.

27. Restrepo A, McEwen JG, Castaneda E. The habitat of Paracoccidioides brasiliensis: how far from solving the riddle? Med Mycol. 2001;39:233-41.
28. Shankar J, Restrepo A, Clemonds KV, et al. Hormones and the resistance of women to paracoccidioidomycosis. Clin Microbiol Rev. 2011;24:296-313. These authors discuss the important role of feminine hormones in resistance to PCM.

29. Restrepo A, Benard G, Castro CC, et al. Pulmonary paracoccidioidomycosis. Semin Respir Crit Care Med. 2008;29: 182-97.

30. Carvalhosa AA, Borges FT, França DCC, et al. Paracoccidioidomycosis prevalence in a public laboratory of the Brazilian Unified Health System. J Oral Diag. 2012;1:31-5. These authors discuss the prevalence of PCM in the public laboratory, using data obtained from cytological and histopathological reports of oral lesions.

31. Restrepo-Moreno A. Ecology of Paracoccidioides brasiliensis. In: Franco MF, del Negro G, da Silva LC, Restrepo-Moreno A, editors. Paracoccidioidomycosis. Boca Raton: CRC Press; 1994. p. 121-8.

32. Fava SC, Fava NC. Epidemiologic surveys of histoplasmin and paracoccidioidin sensitivity in Brazil. Rev Inst Med Trop Sao Paulo. 1998;40:155-64

33. Franco M, Montenegro MR, Mendes RP, et al. Paracoccidioidomycosis: a recently proposed classification of its clinical forms. Rev Soc Bra Med Trop. 1987;20:129-32.

34. Marques SA. Paracoccidioidomycosis: epidemiological, clinical, diagnostic and treatment up-dating. An Bras Dermatol. 2013;88: 700-11. This article reviews important aspects of PCM.

35. Londero AT, Rios-Gonçalves AJ, Terra GMF. Paracoccidioidomycosis in Brazilian children. A critical review (1911-1994). An Bras Ped. 1997;4:128-37.

36. Fonseca ERS, Pardal PPO, Severo LC. Paracoccidioidomicose em crianças em Belém do Pará. Rev Soc Bras Med Trop. 1999;32:313.

37. Resende LS, Mendes RP, Bacchi MM, et al. Bone marrow necrosis related to paracoccidioidomycosis: the first eight cases identified at autopsy. Histopathology. 2009;54:486-9.

38. Pagliari C, Sotto MN. Dendritic cells and pattern of cytokines in paracoccidioidomycosis skin lesions. Am J Dermatopathol. 2003;25:107-12.

39. Marques SA, Cortez DB, Lastoria JC. Paracoccidioidomicose: frequência, morfologia e patogênese de lesões tegumentares. An Bras Dermatol. 2007;82:411-7.

40. Londero AT. Paracoccidioidomicose: patogenia, formas clinicas, manifestacoes pulmonares e diagnóstico. J Pneumol (Brazil). 1986;12:41-57.

41. Alves GRT, Filho L, Derly J, et al. Neuroparacoccidioidomycosis. Rev Soc Bras Med Trop. 2011;44:654. This article reports the clinical characteristics of PCM when affecting the central nervous system.

42. Wanke B, Aidê MA. Chapter 6-paracoccidioidomycosis. J Bras Pneumol. 2009;35:1245-9.

43. Pedroso VSP, Vilela MC, Pedroso ERP, et al. Paracoccidioidomicose com comprometimento do sistema nervoso central: revisão de literatura. Rev Bras Neurol. 2008;44:33-40.

44. Pedroso VS, Vilela MC, Pedroso ER, et al. Paracoccidioidomycosis compromising the central nervous system: a systematic review of the literature. Rev Soc Bras Med Trop. 2009;42:691-7.

45. Andrade ALSS. Paracoccidioidomicose linfático-abdominal. Contribuição ao seu estudo. Rev Pat Trop. 1983;12:165-256.

46. Martinez CAR, Priolli DG, Ramos CO, et al. Paracoccidioidomicose do colon: relato de caso. Arq Med ABC. 2006;31:78-82.

47. Chojniak R, Vieira RAC, Lopes A, et al. Intestinal paracoccidioidomycosis simulating colon câncer. Rev Soc Bras Med Trop. 2000;33:309-12.

48. Alsharif M, Martin AU, Shelton Jr JB, et al. Paracoccidioides brasiliensis in a liquid-based Papanicolaou test from a pregnant woman: report of a case. Diagn Cytopathol. 2008;36:557-60. 
49. Begliomini H, Gorga CF, Franca LC. Prostatic paracoccidioidomycosis, report of a case and review of the literature. J Bras Urol. 1993;19:285-8.

50. Cechella MS, Melo CR, Melo IS, et al. Male genital paracoccidioidomycosis. Rev Inst Med Trop Sao Paulo. 1982;24: 240-5.

51. Severo LC, Kauer CL, Oliveira FM, et al. Paracoccidioidomycosis of the male genital tract. Report of eleven cases and a review of Brazilian literature. Rev Inst Med Trop Sao Paulo. 2000;42:37-40.

52. Marques SA, Tangoda LK, Camargo RMP, et al. Paracoccidioidomycosis of external genitalia: report of six new cases and review of the literature. An Bras Dermatol. 2012;87:235-40. This paper reports the clinical presentations of PCM affecting the genitalia.

53. Lopes DL, Araújo SA, Santos JPLS, et al. Prostatic paracoccidioidomycosis: differential diagnosis of prostate cancer. Mem Inst Osw Cruz. 2009;104:33-6.

54. Araújo SA, Espindola BM, Pedroso ERPP. Cutaneous disseminated paracoccidioidomycosis. Am J Trop Med Hyg. 2012;86:1. This article reports a case of disseminated PCM.

55. Bello AGD, Severo CB, Oliveira FM, et al. Disseminated paracoccidioidomycosis (simulating metastatic lung cancer) and Strongyloides stercoralis hyperinfestation in a steroid-treated patient. J Clin Microbiol. 2011;49:2054-5. This paper presents a case of disseminated PCM associated with strongyloidiasis.

56. Benard G, Duarte AJ. Paracoccidioidomycosis: a model for evaluation of the effects of human immunodeficiency virus infection on the natural history of endemic tropical diseases. Clin Infect Dis. 2000;31:1032-9.
57. Karp CL, Auwaerter PG. Coinfection with HIV and tropical infectious diseases: II. Helminthic, fungal, bacterial and viral pathogens. Clin Infect Dis. 2007;45:1214-20.

58. Castro G, Martinez R. Disseminated paracoccidioidomycosis and coinfection with HIV. N Engl J Med. 2006;355:2677.

59. Corti M, Villafañe MF, Negroni R, et al. Disseminated paracoccidioidomycosis with peripleuritis in an AIDS patient. Rev Inst Med Trop Sao Paulo. 2004;46:47-50.

60. Franco L, Najvar L, Gomez BL, et al. Experimental pulmonary fibrosis induced by P. brasiliensis conidia: measurement of local host responses. Am J Trop Med Hyg. 1998;58:424-30.

61. Tobon AM, Agudelo CA, Osorio ML, et al. Residual pulmonary abnormalities in adult patients with chronic paracoccidioidomycosis: prolonged follow-up after itraconazole therapy. Clin Infect Dis. 2003;37:898-904.

62. Travassos, LR, Taborda CP. New advances in the development of a vaccine against paracoccidioidomycosis. Front Microbiol. 2012;3: 1-6. This article reports the main strategies used so far to develop a vaccine against $P C M$.

63. Taborda CP, Juliano MA, Puccia R, et al. Mapping of the T-cell epitope in the major 43 kilodalton glycoprotein of Paracoccidioides brasiliensis which induces a Th-1 response protective against fungal infection in $\mathrm{BALB} / \mathrm{c}$ mice. Infect Immun. 1998;66:786-93.

64. Travassos LR, Taborda CP, Iwai LK, et al. The gp43 from Paracoccidioides brasiliensis: a major diagnostic antigen and vaccine candidate. In: Domer JE, Kobayashi GS, editors. The Mycota XII: human fungal pathogens. Heidelberg: Springer-Verlag; 2004. p. 279-96. 